\section{THE ELECTRICAL STIMULATION OF NERVES AT OPERATION.}

BY NOEL H. M. BURKE, M.R.C.S., L.R.C.P. LOND., LATSLY MEDICAL OFFICER IN CHARGF OF THE ELECTRICAI DEPARTIIENT, HORTON WAR HOSPITAL, EPSOM.

DURING the years 1915 to 1917 a number of observations on this subject were made at the Horton and Manor War Hospitals at Epsom, and the results obtained, with such lessons as appear to be deducible from the experience gained in a series of some 80 cases, may be of interest.

The first matter to be decided upon is the choice of apparatus and of method, and the following fundamental considerations have led to the adoption of a certain routine.

1. Since a nerve is a small and delicate structure, which at the greatest is little thicker than a pencil, and since access is through the comparatively small opening of an operation wound, the electrode must be compact, easily held and manipulated even in the depths of a small wound, and capable of thorough sterilisation.

2. The surgeon dislikes interruption or interference with the course of his manipulations and the anæsthetist sometimes objects to prolongation of anæsthesia, so that any electrical examination should be rapid and simple.

3. With the direct current it is easy to burn any tissues which are in contact with the electrodes, and though it is possible to lessen this danger by suitable precautions, it is safer to use the induction-coil current only. The results appear to be similar and equally valuable.

After the first few attempts, with varying devices, I have come to regard the following apparatus as meeting all the requirements of practical importance :-

1. A Lewis Jones sledge coil, which is handy and portable and can be put on a chair or stool well out of the way of the operator and his assistants.

2. Two long cables are attached to the terminals of this machine, and their peripheral ends, for about 3 골 4 feet, are cased in good rubber tubing made con. tinuous with the insulation of the bi-polar electrode. The rubber ends can be boiled in the steriliser and thereafter form part of the sterile apparatus for handling by the surgeon and others who are "clean," while the central end above the rubber tubing is unclean, and can be freely handled by the electrologist, nevrologist, or such assistant as may be appointed to control the coil.

3. The electrode I have found most useful is a small telephone plug, with the two pins bent towards each other. Around its junction with the cables rubber tape is tightly wound and the joints sealed with pure rubber solution.

\section{Object of the Examination.}

The functions of the nerve which it is possible to investigate are those of excitability and conductivity. When stimulation of the nerve above the lesion leads to muscular contraction this is mainly evidence of physiological continuity of the nerve through the area of injury - that is to say, a demonstration of conductivity, The excitability of the central end is not likely to suffer to a great extent. Contraction obtained by stimulating below the lesion is mainly evidence of the excitability of the peripheral portion of the nerve trunk. It is also a proof of conductivity in this lower part of the nerve, but the extent to which this must be considered is discussed below. It is necessary, therefore, to examine the result of stimulation of the nerve trunk above and below the level of the lesion, both before and after dissection of the nerve from scar tissue and adhesions. This is not really difficult from the surgeon's point of view, because the majority are cases of compression in scar tissue rather than of complete division, and in most of these the result of the wound and the subsequent scarring has led to deformity from normal relationships. Most surgeons therefore first look for the nerve above and below the wound level, so as to find it easily in its proper position, and then trace it down and up into the area of lesion. This rule applies to nearly all operations for nerve injury, and, indeed, the few operators who try to find the nerve directly in the midst of the area of injury soon find themselves in difficulties, and may do damage. This rule has lately been emphasised by Sir Robert Jones.

\section{Method.}

The first two or three observations were made with a pin electrode on the nerve, and a large indifferent electrode on some distant part of the body. This, however, seemed to be calculated to increase the liability of the stimulation to spread to other structures than the nerve under observa. tion, and to tend to inaccuracy; it also led to the inconvenience of wires diverging to opposite ends of the operating table, instead of both going close together to the site of operation only. For these reasons the small bi-polar electrode was adopted for general use.

Strength of stimulus. - The coil is adjusted to yield the current which experience has shown to be sufficient to produce an obvious contraction in an average normal case. This has been regarded as the standard strength of stimulation, and provides a measure for the rough comparison of results which alone is possible under the conditions already described. Minute measurement is not practicable. The general idea is to use the constant strength and to note the results obtained under varying conditions.

Method of stimulation.--The nerve trunk, having been isolated in its undamaged portion above the lesion, is gently lifted on a hook so as to be free of surrounding structures. The electrode is then applied, so that the two pin terminals lie evenly and lightly on the trunk, the current is turned on, and the result noted. The observation is rapidly repeated, with the electrode applied to different aspects of the nerve surface, in order to pick out separate muscles with greatex accuracy. The same observations are made for the portion of the nerve below the injury. Dissection is then finished, and if the nerve is found to be in anatomical continuity the tests are repeated on the liberated nerve.

Observation.-It is necessary to have good exposure of the hand, foot, or other part in which movement is to be sought for. This part need not be "clean," unless the surgeon himself is making the observation. The examination of the result of stimulation must be done with scrupulous care by someone accustomed to the business, so that a minute muscular contraction is not missed, nor the nature of a movement misinterpreted. For instance, if the median nerve has been stimulated and the thumb moves, it is necessary to be certain whether the movement is of median type and signifies a fairly sound nerve, or of ulnar type due to spreading of the current, and signifying at least much depression of the physiological activity of the median.

\section{Discussion of Observations.}

These examinations were made at first rather with a view to gaining information about the conditions present in nerve injuries than as a means of guiding the surgeon's decision. From the results obtained certain ideas quickly suggested themselves, and will be mentioned below. It is not easy to collect the information into a simple form that is easily read, but an attempt has been made in the 
accompanying table to show the evidence on the main points, and from this evidence certain facts emerge.

Table of Results. Conductivity and Excrtability Before and After Freeing the Nerve.

(a) Complete Division of Nerve (25 cases).

\begin{tabular}{|c|c|c|c|}
\hline \multicolumn{2}{|c|}{ Conductivity. } & \multicolumn{2}{|c|}{ Excitability. } \\
\hline Before. & After. & Before. & After. \\
\hline $\begin{array}{r}19 \text { absent. } \\
6 \text { no test. }\end{array}$ & - & $\begin{array}{l}19 \text { absent. } \\
6 \text { no test. }\end{array}$ & - \\
\hline
\end{tabular}

(b) Nearly C'omplete Division of Nerve (13 cases).

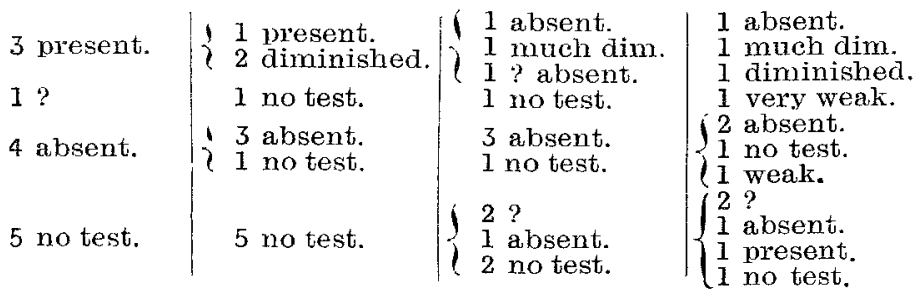

(c) Slight Division of Nerve (2 cases).

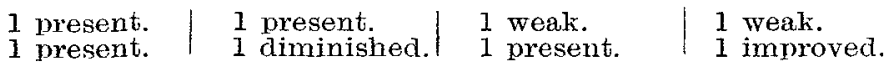

(d) Scar Tissue (12 cases).

\begin{tabular}{|c|c|c|c|}
\hline 19 present.* & $\left\{\begin{array}{l}5 \text { improved. } \\
8 \text { unchanged. } \\
1 \text { absent. }\end{array}\right.$ & & $\left\{\begin{array}{l}8 \text { improved. } \\
5 \text { unchanged. } \\
7 \text { no test. }\end{array}\right.$ \\
\hline $1 ?$ & $\begin{array}{l}5 \text { no test. } \\
1 \text { absent. }\end{array}$ & $1:$ present. & 14 present. \\
\hline 6 absent. 1 & $\left\{\begin{array}{l}2 \text { present. } \\
3 \text { absent. }\end{array}\right.$ & 10 absent. & \\
\hline 16 no test. & 16 no test. & & 1 no test. \\
\hline
\end{tabular}

One had causalgia and no visible or palpable scar. One had two oyerations on the same nerve, at different levels.

One had causalgia and much scar. One had two operations on the same nerve on contiguous portions, the second time not tested.

1. No response was obtained on stimulation of the nerve in any case of complete division.

2. Cases of severe injury amounting to obvious destruction of more than half the cross-section of a nerve showed some response to stimulation in a fair number of instances, and the response was in general diminished after dissection was complete. Sometimes this would suggest that the dissection had divided a few surviving fibres that were much involved in scar tissue but still physiologically active.

3. Among these and other fairly severe cases one or two were noticed which seemed to show fatigue or diminished activity, either as a result of much manipulation or of much stimulation. These were not numerous enough to dogmatise upon, but suggest a line for further investigation.

4. Conductivity when present may be of normal or diminished quality.

5. A muscular contraction in response to stimulation of the central portion of the nerve is proof not only that conductivity is present through the area of injury, but also, of necessity, that it is present in the whole peripheral portion of the nerve. Nevertheless, it is possible to have in this lower portion a diminished or even absent excitability to such stimuli as are applied in this method, although the nerve can conduct an impulse from above.

6. In the two cases where slight division was the predominant feature each gave response, one showing improvement of excitability but diminished conductivity after dissection.

7. The scar cases were, of course, a mixed set, including those which showed no macroscopic evidence of section of fibres and a greater or less degree of fibrous formation about the nerve trunk. The greater number showed a conductivity more or less preserved (19 out of 26 examined), while 20 out of 31 showed excitability. Both qualities were in general improved after neurolysis : only 1 case showed a diminution, and this was of conductivity.
8. It is only with a fairly sound nerve that anything like a general contraction of the whole muscle group is seen. Mostly one gets only a contraction of one or two larger muscles. This is a drawback in estimating the condition of the nerve from the results seen in such a state as partial division, as the contraction produced does not necessarily mean that no fibres have been divided.

9. It is easy when stimulating a seriously injured nerve to get a contraction of muscles supplied by a neighbouring healthy nerve, somewhat as is seen in ordinary clinical muscle testing. This spreading of stimulation is lessened if the nerve is held up on a hook away from other tissues, so that the maximum intensity of the current is applied to the nerve, and can only get to neighbouring tissues through its long axis.

10. It has been very instructive to examine, treat, and repcrt on cases before operation, and then to go and see what condition was actually found on the table. It has also been a help, in deciding on the course of treatment after operation, to know exactly what has been done.

11. For these reasons, and because he has the responsibility of the greater part of the period of treatment in these cases, the electrotherapist should collaborate closely with the surgeon and should attend the operations on his patients whenever possible.

12. One way in which the experience of this series has been of interest is in the light it has thrown on the accuracy of diagnostic methods and their interpretation. The reports from the electrical department endeavoured to indicate the probable degree of injury (complete division, much scar tissue, division of a few fibres only, \&c.) and comparison of the opinions given in reports before operation and the actual findings shows the following results : Diagnosis correct, 41 cases ; approximately correct, 18 ; about half right, 11 ; about a quarter right, 1 ; quite wrong, 1 . The error was due to optimistic interpretation in 13 cases and five times to pessimism.

\section{Conclusions and Lessons.}

(1) Every case should be tested, as a fair number of decisions are made easier by the information obtained and an unnecessary section of an undivided nerve may be thereby avoided. This was strongly brought home in a recent case, not included in the series, where the median nerve had been exposed high in the axilla. The surgeon, his assistant, and $I$ all felt the mass of scar tissue into which the nerve was traced, and all thought we detected a definite end to the nerve course. On stimulation, however, contraction was obtained. Without this demonstration it is quite probable that the nerre would have been divided at its apparent cut end in order to make further dissection simpler.

(2) Conductivity is conclusive evidence of physiological continuity of nerve fibres, as also is excitability below the lesion.

(3) Improvement in conductivity or in peripheral excitability following immediately after neurolysis is suggestive of only slight compression and possibly chemical nerve-block.

(4) Absence of conductivity and of excitability, even after neurolysis, is not conclusive evidence of division, but is probably an indication of fairly severe nerve disturbance.

I have to express my thanks for the ready kindness of the surgeons who have allowed me to make my investigations while they operated: Major H. Makin and Captains $G$. Owen and $J$. McGee, of the Australian Imperial Force; Majors A. Paling, M. G. Riches, and A. F. Stabb, and Captain Lawson Whale, of the R.A.M.C.; and Mr. V. S. Fenwick and Mr. R. Warren, who were consulting surgeons to Horton War Hospital. I have also to thank Lieutenant-Colonels J. R. Lord and S. Elgee, R.A.M.C. officers commanding the two hospitals, for kind permission to publish this paper. 